\title{
A infraestrutura rodoviária e a urbanização regional contemporânea no território paulista: o caso do corredor urbano Campinas-Sorocaba, Brasil
}

Wilson R. Santos Jr. Pontifícia Universidade Católica de Campinas, São Paulo, Brasil. Anderson D. A. Proença. Pontifícia Universidade Católica de Campinas, Santo André, Brasil.

RESUMO | Aborda-se neste texto a constituição de articulaçóes urbanas que extrapolam a dimensão metropolitana, espraiando-se de forma dispersa em escala regional, utilizando como estudo de caso a formação de um "corredor urbano" entre Campinas e Sorocaba, duas cidades polos de regióes metropolitanas no interior do Estado de São Paulo, Brasil. Constata que o sistema de transporte regional articula a configuração de um eixo de conurbação linear entre as duas regióes metropolitanas, ao longo do qual há uma intensa dinâmica de transformação espacial com o rápido avanço do tecido urbano - especialmente nas tipologias de condomínios industriais e loteamentos residenciais fechados - sobre áreas rurais. Demonstra-se assim, uma nova tendência de concentração linear da dispersão urbano-regional no contexto de uma urbanização extensiva que se manifesta em vetores privilegiados em relação à afluência de investimentos, principalmente dos setores produtivos mais vinculados à economia globalizada, confrontando as tradicionais divisóes conceituais entre urbano/rural, cidade/ região, centro/periferia.

PALAVRAS-CHAVE | morfologia urbana, redes, reestruturação territorial.

ABSTRACT | This paper is about the constitution of urban articulations extended beyond the metropolitan scale, spreading in a dispersed pattern on a regional scale, using the formation of an "urban corridor" between Campinas and Sorocaba, two core-cities of distinct metropolitan areas in the interior of the State of São Paulo as case studies. The regional transport system is the element that articulates the configuration of a linear axis of conurbation between the two metropolitan areas, during which there is an intense spatial transformation with the quick advance of the urbanized areas - especially in the types of gated communities - over rural areas. This shows a new trend of linear concentration of regional dispersion of urban areas in some privileged vectors, in relation to the inflow of investments, mainly of the productive sectors linked to the globalized economy, confronting the traditional conceptual divisions between urban/rural, city/region, center/periphery.

KEYWORDS | networks, urban morphology, territorial restructuring.

Recebido em 30 de junho de 2018, aprovado em 28 de janeiro de 2019.

E-mails: W. R. Santos Jr., wilson@puc-campinas.edu.br|A. D. A. Proença, anderson.d.proenca@gmail.com 


\section{Introduçáo}

As profundas transformaçóes nas dinâmicas de produção do espaço urbano associadas à reestruturação em escala mundial do sistema capitalista a partir das últimas décadas do século passado, constituíram-se como um novo marco conceitual que embasa grande parte das temáticas atuais nos campos do urbanismo e do planejamento urbano. Sob este novo paradigma constata-se, em diversas partes do mundo, a formação de articulaçóes urbanas em escala regional que estão estreitamente relacionadas à uma nova fase da dialética territorial de dispersáo-concentração espacial das estruturas produtivas. Do ponto de vista da organização territorial, expressa uma mudança no paradigma de polos regionais de industrialização - conceito que impulsionou o desenvolvimento econômico dos países de industrialização tardia ao longo da segunda metade do século $\mathrm{xx}$-, para a constituição de novos vetores inter-regionais de reconcentração da atividade produtiva ao longo de vias de transporte regional de grande porte, mais atrativos ao recebimento de atividades econômicas mais modernas.

É neste contexto que o presente artigo objetiva demonstrar a constituição de um corredor urbano entre as regióes metropolitanas de Campinas e Sorocaba, conceituando-o como um dos vetores de maior intensidade de urbanização dentro em uma "macro-regiâo urbanizada", a Megalópole do Sudeste (Queiroga, 2001), que envolve boa parte do território do Estado de Sáo Paulo e partes dos estados de Minas Gerais e Rio de Janeiro. Adota uma abordagem estruturalista que, a partir da relação entre as infraestruturas de transporte e os movimentos de dispersão urbana em escala regional, relaciona o fenômeno urbano empírico de dispersão e fragmentação urbana em escala local/regional, aos processos de integração da cadeia produtiva, em escala global. Destaca-se que este trabalho realiza uma abordagem metodológica especificamente sobre as transformaçóes urbanas em escala regional, adequado à verificação dos novos fenômenos urbanos dispersos que conformam a articulação urbano-regional entre Campinas e Sorocaba.

$\mathrm{O}$ texto divide-se em quatro partes, além da introdução e das consideraçóes finais. As duas primeiras partes tratam de uma análise sobre o que se considera o momento de inflexão na dinâmica de urbanização brasileira nas últimas décadas do século xx, a crise do modelo de industrialização por substituição de importações e o fortalecimento da cadeia produtiva "flexível" - fenômeno mais intenso em algumas regióes do que outras - típica do atual período de globalização. Foca nos movimentos de concentração e dispersão da urbanização associados a estes dois períodos da evolução do sistema econômico e da urbanização do território, brasileiro no geral, e paulista em particular.

$\mathrm{Na}$ terceira parte analisa-se propriamente a formação do corredor urbano entre Campinas e Sorocaba, manifestado na constituição de um eixo linear de intensa expansão urbana ao longo das últimas duas décadas, conformando um continuum urbano entre cinco municípios ao longo da rodovia SP-75. Utiliza-se de análises morfológicas sobre a expansão urbana recente e sobre as mudanças nas tipologias urbanas predominantes, como metodologia para criar um quadro de caracterizaçáo atual da urbanização neste recorte territorial. Demonstra-se assim a tendência à 
configuração de um eixo linear de conurbação ininterrupta entre as duas cidades a partir da implantação de clusters industriais e empresariais, e de condomínios e loteamentos residenciais fechados ao longo da rodovia SP-75, apoiados no potencial de circulação e mobilidade regional proporcionados pela rodovia.

$\mathrm{Na}$ quarta e última parte, é analisado o papel das infraestruturas de transporte inter-regional na expansão urbana recente no eixo territorial entre Campinas e Sorocaba, relacionando a constituição do corredor urbano Campinas-Sorocaba à concentração de grandes volumes de investimentos estatais em infraestrutura de transporte e circulação com o objetivo de ampliar a capacidade de fluxos de mercadorias em relação tanto ao mercado consumidor local e nacional, quanto à cadeia produtiva internacional. Evidencia, portanto, que a formação do corredor urbano está associada à uma estratégia - por parte de diversos agentes que atuam sobre o território - de concentração de atividade produtiva, especialmente de alta tecnologia, neste vetor territorial.

\section{Formação das primeiras metrópoles nacionais durante o período de industrialização por substituiçáo de importaçóes}

A partir de meados do século xx foram implementadas políticas de desenvolvimento econômico e de integraçáo do mercado consumidor nacional que incidiram diretamente na formação das primeiras metrópoles nacionais em algumas capitais de estados brasileiros caracterizadas pelo vertiginoso processo de crescimento urbano e concentração populacional em relação ao restante do território brasileiro. Foi o período em que houve uma "explosão urbana" (Santos, 1994) nestas cidades, traçando as características que viriam a marcar o desenvolvimento metropolitano no Brasil (e também no restante da América Latina, no geral); como a composição de um tecido urbano denso e compacto ao redor de uma centralidade principal nucleadora da malha metropolitana; a clara divisão entre o "fim da cidade" e o espaço rural circundante à metrópole; e as fortes desigualdades socioespaciais entre os espaços urbanos central e periférico, com o surgimento de grandes bolsóes de pobreza nas bordas das metrópoles.

A política de industrialização no modelo de substituição de importaçóes vigorou como um dos principais programas políticos no Brasil entre as décadas de $1940 \mathrm{e}$ 1960. Visava a criação, por parte do Estado, de indústrias de base - também denominadas como indústrias de bens intermediários, como siderúrgicas e refinarias de petróleo, por sua condição de fabricação de produtos que servem de matéria-prima para a produção e montagem de outras mercadorias industrializadas - em diversas regiốes do país, de forma a alimentar o crescimento da produção industrial manufatureira nacional e assim diminuir a dependência de importaçóes de produtos manufaturados externos. Neste contexto consolidou-se o padrão rodoviário de circulação tanto no espaço intra-urbano quanto inter-regional, a partir do Plano de Metas criado durante o governo Juscelino Kubitschek em 1955, que promoveu a abertura da economia nacional aos investimentos estrangeiros e à implantação da indústria automobilística no país (Queiroga, 2001). Esta decisão política deu início à uma simbiose que perdura até à atualidade, no qual os investimentos em rodovias 
foram um dos fatores mais determinantes na expansão industrial (e justamente por São Paulo contar com melhores redes de transporte, também teve maior crescimento industrial e urbano), que por sua vez aumentava a demanda por expansão e melhorias de rodovias. As vantagens da concentração demográfica e de atividades industriais em determinados pontos do território eram evidentes neste período. Em um território entáo com baixo nível de desenvolvimento das estruturas produtivas capitalistas, a aglomeração das forças produtivas em um número limitado de cidades criava as melhores condiçôes possíveis para um rápido desenvolvimento industrial, propiciado pelas vantagens trazidas pelas "economias de aglomeração". Assim as empresas de diferentes setores compartilhavam vantagens locacionais, tanto relacionadas à proximidade às fontes de matéria-prima e aos principais mercados consumidores, concentração de mão-de-obra, e às principais infraestruturas de transporte de mercadorias; quanto no desenvolvimento de uma cooperação mútua que potencializavam suas respectivas capacidades produtivas (Benko, 1999).

A concentraçáo de investimentos industriais em algumas capitais reforçou a característica histórica de organização do território nacional enquanto um "grande arquipélago, formado por subespaços que evoluíram, segundo lógicas próprias, ditadas em grande parte por suas relaçóes com o mundo exterior" (Santos, 1994, p. 29). Os investimentos em infraestruturas de indução da industrialização (como a construção de infraestruturas de transportes e comunicação, e a criação de universidades e institutos de pesquisa) ocorreram predominantemente de forma pontual nas imediaçóes das cidades mais importantes no desenvolvimento econômico nacional nos períodos anteriores, acentuando assim a concentração demográfica em algumas poucas áreas urbanas do país. $\mathrm{Na}$ prática, induziu-se à constituição de grandes metrópoles industriais em meio a regióes de baixo desenvolvimento econômico e social.

As metrópoles industriais absorviam a grande massa populacional que se deslocava do campo para as cidades em busca de postos de trabalho ofertados pelo crescimento industrial, causando uma intensa corrente migratória do campo à cidade. Segundo Santos (1994), o aumento do total de população urbana no Brasil foi de $653,03 \%$ entre 1940 e 1980, com um acréscimo médio de $111,53 \%$ entre as décadas de 1970 e 1980 e de 107,66\% entre 1980 e 1990 (Santos, 1994). Contudo, a industrialização brasileira não se consolidou de forma a absorver toda mão-de-obra recém-chegada às cidades, causando o aumento da pobreza do desemprego nas metrópoles industriais que, por sua vez, contrastavam com a riqueza gerada pelas indústrias.

Desta forma consolidaram-se as características mais marcantes das metrópoles industriais que se estabeleceram na América Latina em meados do século xx. Foi o período que Lacerda (2012) classificou como o predomínio de uma "urbanização polarizada”, com a formação de tecidos metropolitanos densos organizados em torno de uma centralidade que exercia forte poder nucleador das atividades econômicas e da expansão urbana da cidade. Acentuava-se o contraste formado pela desigualdade socioespacial entre os bairros centrais concentradores de população e atividade comercial e de serviços de maior renda, e as extensas áreas periféricas que recebiam a maior parte da população pobre que migrava de áreas rurais e de cidades 
pequenas, marcadas pela inexistência ou precariedade de infraestrutura urbana básica e serviços públicos (Lacerda, 2012).

Pode-se afirmar então que durante as décadas de 1940 e 1980 predominou o padrão de urbanização concentrada no Brasil, com um crescimento vertiginoso tanto das principais metrópoles (com população acima de um milhão de habitantes), quanto das grandes cidades médias (com população em torno de meio milhão). Como apontou Santos (1994), as cidades acima de 100 mil habitantes passaram de 11 em 1940, para 95 em 1980, e as com população acima de 500 mil foram de 2 para 14 cidades entre 1940 e 1980 (Santos, 1994, p.82). Tal fenômeno não se manifestou apenas em termos demográficos associados à concentração de população em poucas metrópoles e cidades grandes, mas refletiu também na organização morfológica espacial destas urbes. Os altos níveis de concentração e a densidade eram claramente as características morfológicas mais marcantes da metrópole industrial, fenômenos associados à disputa pelo espaço intra-urbano em relação à proximidade das principais centralidades e às melhores condiçôes de acessibilidade. Assim como afirmou Secchi (2015):

[...] a figura da concentração organizou com tal força o pensamento sobre a cidade e a sociedade urbana que fez a concentração parecer uma característica própria e unívoca da cidade e uma tendência inexoravelmente previsível do futuro, escondendo com isso, por longo tempo, tendências e mudanças evidentes. (p. 30)

Reforçou-se assim as distinçôes conceituais existentes no campo urbanístico entre centro/periferia, urbano/rural e cidade/região. A consolidação da metrópole industrial enquanto um tecido urbano denso e contínuo, com limites e organização formal nítidas, induzia a compreensão do espaço urbano - da cidade - como uma organização socioespacial de visível homogeneidade interna e clara distinção morfológica em relação ao espaço rural - da região. De maneira semelhante, também se consolidou uma cisão clara entre as áreas centrais concentradoras da urbanização formal, onde se localizavam as principais áreas comerciais e de serviços orbitadas pelos bairros de população de alta e média renda, e a extensa periferia informal, onde se localizavam a população mais pobre da cidade que, no caso das metrópoles latino-americanas, compunham a maior parte do tecido urbano (Lacerda, 2012).

As metrópoles nacionais eram entáo espaços circunscritos com alta densidade construtiva e populacional, onde havia uma rápida dinâmica de circulação de ideias e informaçóes, em direta oposiçáo ao espaço do campo então caracterizado pela baixa densidade construtiva e lenta penetração de tecnologias de comunicação e informação. Da mesma maneira que era clara a distinção entre as áreas centrais, onde se concentravam as principais atividades econômicas e a vida cultural da cidade, em oposição a "monotonia" de usos e funçôes das áreas periféricas, destinadas quase exclusivamente ao uso habitacional - e na maior parte, para a população de menor renda.

Entretanto, o acelerado e desmedido crescimento das metrópoles industriais nacionais, aliado às mudanças no paradigma de organização da estrutura produtiva e da divisão socioespacial do trabalho em escala internacional, rapidamente induziram ao surgimento de forças contrárias, no sentido da dispersão das estruturas 
produtivas e da urbanização. Esta tendência já era perceptível na virada entre as décadas de 1970 e 1980, especialmente no Estado de São Paulo, como resposta às "deseconomias de aglomeraçáo" provocadas por fatores inerentes à condiçáo metropolitana, como o alto custo da terra no espaço intra-urbano, as dificuldades de transporte de pessoas e circulação de mercadorias, e o aumento do salário médio e a organização sindical dos trabalhadores nas áreas metropolitanas.

\section{Desconcentração industrial e a urbanizaçáo regional no Estado de Sáo Paulo}

As tendências de concentração e desconcentração geográfica da estrutura produtiva são dinâmicas inerentes à expansão territorial do sistema capitalista. Como apontou Harvey (2005), os processos de aparente dispersão ou concentração das aglomeraçôes urbanas relacionam-se diretamente às condiçóes que, em um determinado período, são mais propícias para a superação de barreiras necessárias ao crescimento progressivo da acumulação de capital. Diversas questóes equacionam-se de maneira a ditar as formas predominantes de organização espacial das atividades produtivas no território, como a distância em relação às fontes de matéria-prima/mercado consumidor, disposição das infraestruturas de circulação de mercadorias, disponibilidade e qualificação da mão-de-obra, quantidade de excedente de capital disponível, entre outros (Harvey, 2005). Desta forma, dois movimentos acabam se sucedendo na disposição territorial das atividades produtivas; uma concentração das atividades econômicas que permite se aproveitar das economias de aglomeraçáo, seguida de uma desconcentração afim de evitar as crescentes "deseconomias de aglomeraçáo" produzidas pela excessiva aglomeração de atividades em um ponto do território (Singer, 1973).

Os movimentos de dispersão/concentração geográfica expressam-se na sucessão histórica de fases da industrialização paulista. No primeiro ciclo de industrialização, na virada entre os séculos XIX/Xx, as fábricas tendiam a localizar-se de forma dispersa e distantes dos principais centros urbanos já que, com o baixo nível de desenvolvimento das infraestruturas de transporte, a proximidade às matérias-primas era o fator mais importante na localização das plantas industriais. Assim a maior parte das primeiras instalaçôes industriais paulistas buscou localizar-se nas imediaçôes das principais fontes de matéria-prima, criando um núcleo urbano multifuncional onde estavam instaladas as habitaçóes, escolas, postos de saúde e centros de lazer para seus trabalhadores (Correia, 2009). Foi apenas a partir da década de 1930, com o crescente investimento em infraestruturas de transporte inter-regional (das primeiras rodovias à expansão portuária) que se consolidou a dinâmica de concentração industrial nos principais centros urbanos.

Com estas afirmações demonstra-se que a desconcentração territorial não é um fenômeno novo e exclusivo do período contemporâneo de urbanizaçáo. O que há de novo são as formas, as características e as tipologias - quantitativas e qualitativas - que se manifestam na dispersão do espaço urbano. Em outros termos, são novas "formas de cidade" que incidem diretamente em novos modos de vida de seus habitantes, que adquirem maior mobilidade territorial e assim potencializam as relaçôes de trabalho, estudos e lazer em escala inter-metropolitana e regional. Amplia-se a escala de relaçóes urbanas e a própria noção de cidade, que passa a ser vivida não 
apenas como um núcleo urbano compacto, mas como a um arranjo regional entre fragmentos dispersos e centros urbanos consolidados.

A crise global do modelo fordista de organização da cadeia produtiva, caracterizada por "técnicas repetitivas de produção em série para mercados de massa" levou a profundas transformaçóes na divisão internacional do trabalho, mais evidentes a partir da década de 1970. Desta forma, foi se consolidando o paradigma "flexível" ou "toyotista" na organização da cadeia produtiva, caracterizada pela maior rotatividade da máo-de-obra, especialização dos trabalhos industriais, privatização e enxugamento das empresas estatais e um mercado de consumo individualizado e privatizado (Boddy, 1990). O desenvolvimento de novas tecnologias de informação e comunicação, que passaram a permitir a circulação instantânea de ideias e informaçôes em praticamente todas as partes do globo, foi crucial na intensificação da internacionalização do sistema produtivo mundial (Castells, 1999).

$\mathrm{Na}$ América Latina tal processo se traduziu na crise do modelo de industrialização baseado na substituição de importaçôes, que havia induzido à formação de grandes aglomeraçóes urbanas concentradoras de atividades econômicas e industriais, em contraste com vastas regióes agrícolas de baixa densidade construtiva e habitacional. No caso específico do Estado de São Paulo, este momento de transição do paradigma econômico ficou marcado pela "desconcentração industrial" caracterizada, inicialmente, pela saída de diversas empresas da Grande São Paulo e um intenso crescimento da produção industrial em algumas regióes do interior do Estado a partir da década de 1970. A expansão industrial ocorreu não apenas em número de empresas que se deslocavam para o interior, mas especialmente na instalação de novas plantas industriais de eletrônicos, informática e outros setores que empregavam métodos mais modernos de produção, ou seja, na fabricação de mercadorias com maior valor agregado. No curto período entre 1970 e 1985 o interior passou de $25,3 \%$ para representar $43,4 \%$ do total do Valor de Transformação do produto Industrial (vTi) do estado, enquanto a capital, São Paulo (desconsiderando a regiáo metropolitana), caiu de $48,1 \%$ para $29,8 \%$, segundo indicadores da Fundação Sistema Estadual de Análise de Dados (Seade) em 2014.

É preciso ressaltar que a desconcentração industrial significou muito mais o estímulo à expansão da atividade industrial em regiôes que já apresentavam índices econômicos elevados, do que o surgimento de novos polos industriais pelo país, atingindo de maneira muito mais acentuada o estado paulista que as outras unidades federativas da nação. O Estado de São Paulo manteve seu status de concentrador da produção econômica nacional, com apenas uma leve queda ao passar de 39,5\% para 36,6\% do total do PIв (Produto Interno Bruto) brasileiro entre 1970 e 1995, período auge da desconcentração industrial (Cano, 2007). Significa então que o crescimento industrial do interior paulista náo significou o declínio econômico da capital; pelo contrário, consolidou-a como principal centro de decisóes financeiras e empresariais, sede da maior parte das principais bancos e empresas nacionais e multinacionais instalados no país - mantendo, inclusive, a sede da maior parte das indústrias que se deslocavam para o interior.

A expansão da atividade industrial pelo interior paulista decorreu, em um primeiro momento, de forma mais acentuada em um raio de aproximadamente $100 \mathrm{~km}$ da 
capital, com foco nas regióes de Campinas, São José dos Campos, Sorocaba e Santos. Desde então a urbanização destas regiōes foi mais intensa, passando estas a constituir quatro das cinco regióes metropolitanas do interior do estado. $\mathrm{O}$ acelerado crescimento urbano e demográfico nestas regióes desde a década de 1970 tem levado à formação de uma complexa rede urbana com alta densidade técnica e intensidade de circulação de pessoas, mercadorias e informaçóes, conceituada como Complexo Metropolitano Expandido ou Macrometrópole Paulista (estes dois últimos termos elaborados pelo governo do Estado de São Paulo, envolvendo a Grande São Paulo e as regióes metropolitanas acima citadas), e Megalópole do Sudeste (conceito que envolve o fenômeno urbano-regional independentemente das divisóes administrativas estaduais, considerando partes dos estados do Rio de Janeiro e Minas Gerais).

A formação da Megalópole do Sudeste é a principal expressão da constituição de uma megarregião urbana que integra as dinâmicas socioespaciais de diversas metrópoles e aglomeraçóes urbanas nos estados de São Paulo, Rio de Janeiro e Minas Gerais, como demonstra a figura 1 (Queiroga, 2001). Relaciona-se diretamente à difusão da atividade industrial pelo interior do Estado de São Paulo e em algumas regióes de Rio de Janeiro e Minas Gerais e está associada às mudanças ocorridas no paradigma produtivo internacional desde a década de 1970 . O protagonismo da região sudeste do país e, especialmente, do estado paulista, manteve-se graças à maior densidade de infraestruturas de transporte e ao maior ritmo de avanço das tecnologias de informação e comunicação em relação ao restante do país, atraindo maior número de empresas para se localizar neste território.

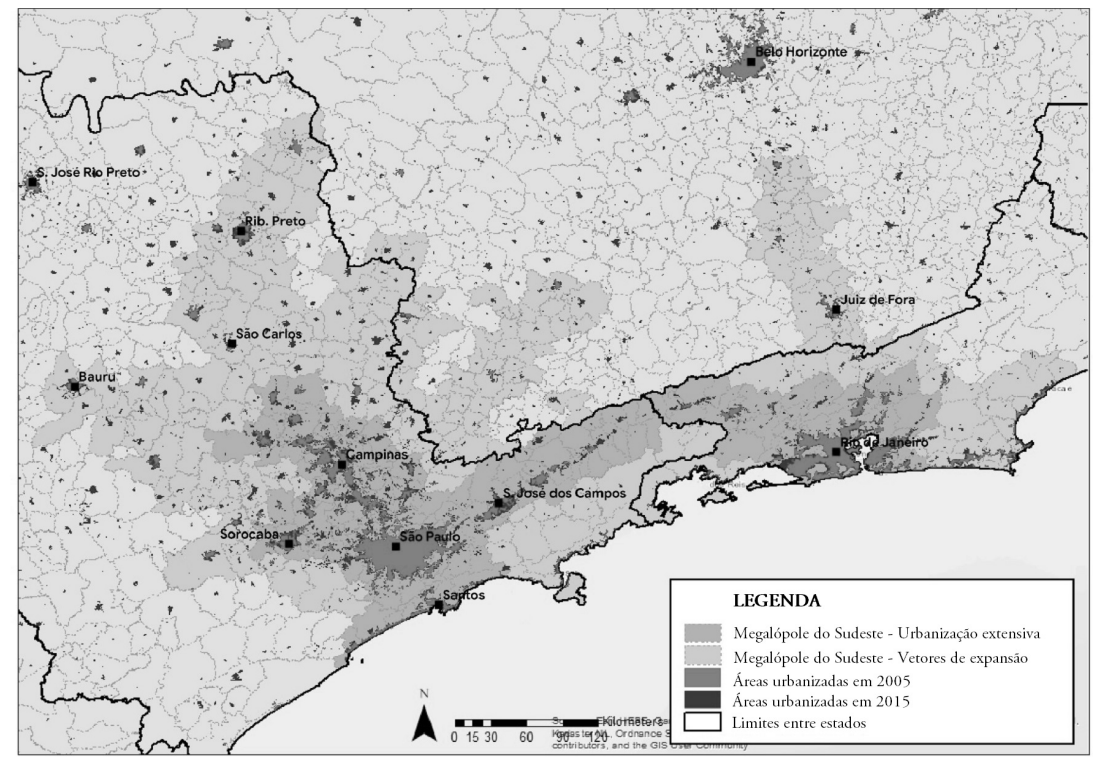

FIGURA I | Megalópole do sudeste e seus principais eixos de expansão

FONTE: ELABORAÇÃO PRÓPRIA 
No Estado de São Paulo várias rodovias foram construídas ou ampliadas neste período com o objetivo de expandir a capacidade de transporte de pessoas e mercadorias entre as regióes do interior, a capital e o porto de Santos. Atendiam-se assim as maiores demandas de circulação de mercadorias da cadeia produtiva "toyotista", caracterizada pela elevada fragmentação em relação ao período anterior de industrializaçáo, na qual os diversos componentes de um produto são fabricados em locais distintos e reunidos para montagem em um ponto do território. Algumas regiôes foram favorecidas neste processo ao receber maior quantidade de investimentos de ampliação da infraestrutura rodoviária, como Campinas e Sorocaba, constituindo importantes entroncamentos rodoviários para os quais convergiam fluxos de outras regióes de São Paulo e outros estados do país.

A expansão e ampliação de eixos viários realizadas pelo Estado de São Paulo, que serão tratadas nas duas últimas partes deste artigo, é um fator que tem influenciado fortemente a urbanização paulista desde a década de 1980. Utiliza-se este recorte temporal por ser uma referência do período em que as tipologias urbanas fechadas passaram a se localizar próximas aos eixos de transporte inter-regional afastando-se dos núcleos urbanos tradicionais, onde os loteamentos e condomínios residenciais fechados e os shopping-centers se popularizaram - apesar dos mesmos terem surgido na virada entre as décadas de 1960 e 1970, tendo o grande loteamento de Alphaville na Grande São Paulo como grande exemplo paradigmático (Raposo, 2012).

A rede de rodovias e vias expressas constituiu-se como um dos elementos de maior indução da dispersão de núcleos urbanos espacialmente fragmentados em relação aos tecidos urbanos tradicionais, suplantando o crescimento denso e contínuo ao redor do centro histórico como morfologia predominante de expansão de áreas urbanizadas. Este fenômeno foi particularmente acentuado no interior paulista, devido a fatores como a disponibilidade e o relativo baixo valor das glebas de terra mais distantes dos centros urbanos, a presença de rodovias inter-regionais e os níveis mais elevados da renda média da população em relação ao restante do país. Como se abordará a seguir, o eixo entre as regiôes de Campinas e Sorocaba é um dos exemplos mais evidentes da intensidade deste processo, induzindo à configuraçáo, na escala metropolitana, de um corredor urbano-regional entre as duas cidades.

\section{A formação do corredor urbano Campinas-Sorocaba}

A constituição de um eixo linear de urbanização praticamente ininterrupto ao longo da rodovia SP-75 entre as cidades de Campinas e Sorocaba, em uma distância média de $90 \mathrm{~km}$ da capital do estado, engloba áreas de seis municípios no Estado de São Paulo: Campinas, Indaiatuba (Metropolitana de Campinas), Salto, Itu, Sorocaba e Votorantim (Região Metropolitana de Sorocaba). Como mostra o mapa da figura 2, os seis municípios compóem um vetor linear diagonal em relação a capital, São Paulo, e têm uma clara ligação morfológica com o tecido urbano de outras conurbaçóes, como os aglomerados urbanos de Jundiaí e Piracicaba. Por corredor urbano se compreende as articulaçóes urbano-regionais que se desenvolvem linearmente ao longo de infraestruturas de transporte com grande fluxo inter-regional. 


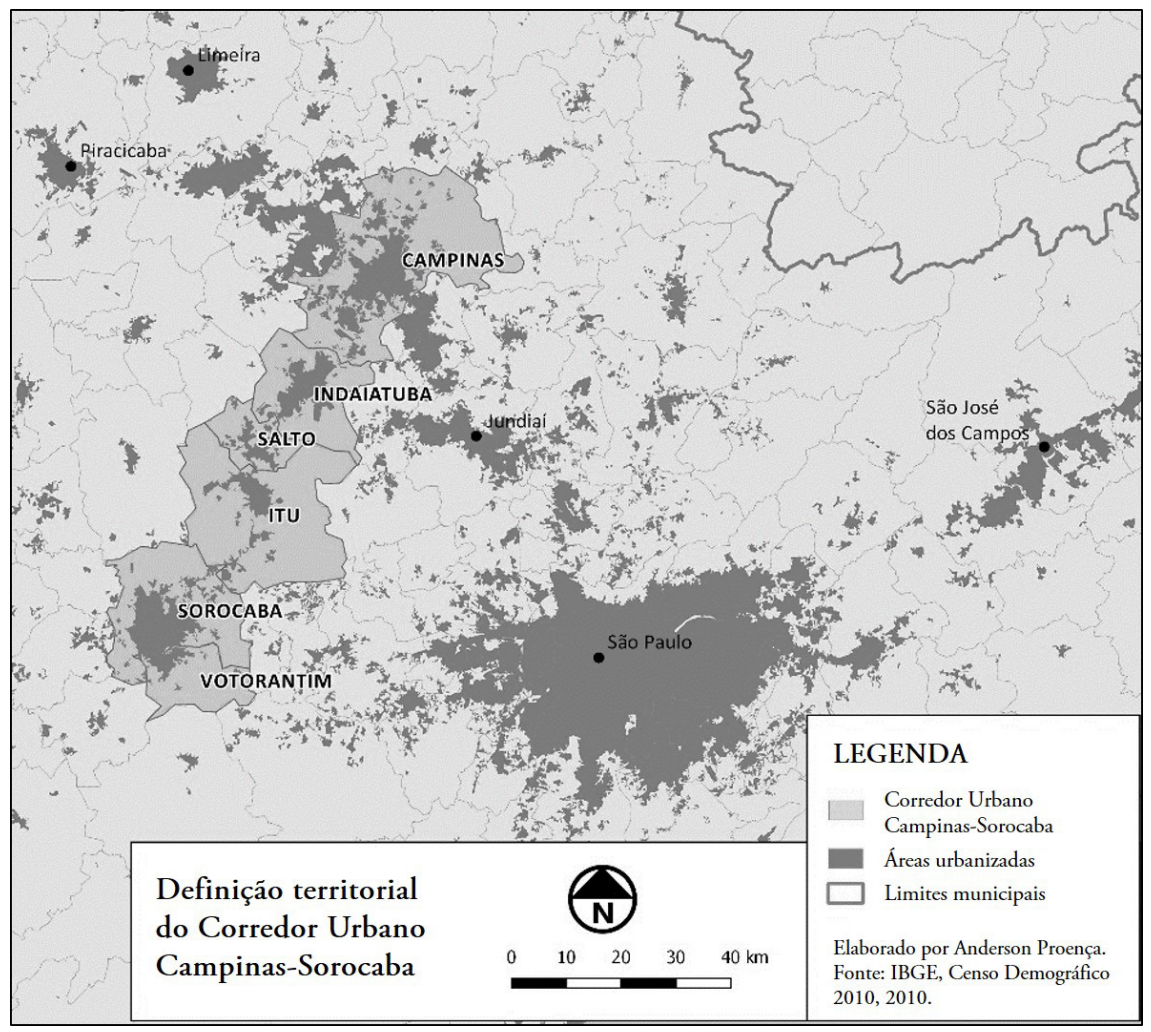

FIGURA 2 | Delimitação territorial do corredor urbano Campinas-Sorocaba FONTE: ELABORAÇÁO PRÓPRIA

A formação de corredores lineares de urbanização não é um processo novo. Estes fenômenos vêm sendo notados no território brasileiro desde a segunda metade do século passado, especialmente no eixo entre São Paulo e Rio de Janeiro ao longo da rodovia Presidente Dutra (BR-I I6), e entre Sáo Paulo e Campinas ao longo da rodovia Anhanguera (sP-330). Também se manifesta em regiôes de urbanização menos intensa e distantes de contextos espaciais propriamente metropolitanos, como por exemplo, nos casos do Vale do Itajaí no Estado de Santa Catarina, e no Vale do Aço em Minas Gerais, onde o principal indutor do fenômeno de conurbação linear, no caso, é a topografia acidentada. Nesses casos citados, a escala e a natureza do processo são distintas, compondo um fenômeno de área urbanizada de menores dimensóes e menor expressão demográfica e econômica em relação ao objeto deste texto.

O componente de novidade, nesse caso, é a formação de um corredor urbanizado ao longo de um vetor territorial que não está diretamente conectado à capital do estado. As dinâmicas de expansão da urbanização em escala regional tradicionalmente se desenhavam a partir da capital em direção ao interior, ao longo das principais vias de transporte interestadual. Assim foram se formando eixos lineares de 
urbanização ao longo da Rodovia Anhanguera entre São Paulo, Jundiaí, Campinas e Americana, ao longo da Rodovia Presidente Dutra entre a capital, São José dos Campos e Taubaté e, com menor intensidade, entre a capital, São Roque e Sorocaba ao longo da Rodovia Raposo Tavares. A composição destes fenômenos territoriais corroborava a ideia de expansão direta da metropolização da capital para o interior do estado, como reflexo do processo de desconcentração das estruturas produtivas a partir da segunda metade do século xx.

A constituição de fenômenos urbanos em escala regional e mais distantes da capital, já na década de 1990, evidencia a maior complexidade territorial da urbanização contemporânea no Estado de São Paulo. A predominância exercida pelas autoestradas como elementos de atração e organização da expansão urbana contemporânea induzem a transformaçóes nos padrões de expansão da área urbanizada com a crescente dispersão de fragmentos urbanos ao longo dos principais eixos viários. As novas tipologias que predominam na expansão urbana ao longo das rodovias inter-regionais apoiam-se justamente na maior escala de mobilidade promovida pelas mesmas, e na possibilidade de deslocamento cotidiano a diversas regiôes metropolitanas e aglomeraçóes urbanas.

A ocupação histórica do eixo entre as regiōes de Campinas e de Sorocaba está diretamente relacionada à evoluçáo técnica das infraestruturas de transporte inter-regional. A primeira ligação entre as duas regiôes remonta ao final do século XIX com a construção de ramais ferroviários das companhias Ytuana (1873) e Sorocabana (1892), implantadas com o objetivo principal de escoar a produção agrícola do interior - especialmente de café, entâo principal produto de exportação nacional - até o porto de Santos, no litoral paulista. Foi nesse período que surgiram e se expandiram, ao redor de estaçóes de parada destas ferrovias, os núcleos urbanos que culminariam nos atuais municípios de Indaiatuba e Salto, além de um novo impulso na expansão da malha urbana dos já existentes núcleos urbanos de Sorocaba, Itu e Campinas.

Na década de 1920 iniciou-se um progressivo processo de substituição das ferrovias pelo modal rodoviário como principal meio de circulação inter-regional de pessoas e mercadorias no Brasil e, ainda mais intensamente, no Estado de São Paulo. Entre as décadas de 1920 e 1930 foram construídas as primeiras estradas rodoviárias no estado, fazendo a ligaçâo entre a capital e o interior em vias de pista simples e trajetos tortuosos. Entre as décadas de 1940 e 1950 foi implantada a primeira geração de autoestradas no estado paulista, dentre as quais as rodovias Raposo Tavares (SP-270) entre a capital e Sorocaba, e Anhanguera (SP-330) entre São Paulo e Campinas. Por fim, entre as décadas de 1970 e 1980, iniciou-se a construção de uma nova geração de autoestradas, algumas delas confinadas, com traçados mais retilíneos e com maior número de faixas de rodagem, permitindo maior capacidade de fluxo que as autoestradas anteriores.

Contudo, foi apenas na década de 1980 que se realizou a construção primeira auto-estrada entre Campinas e Sorocaba, a sP-75, com 77,6 km de extensão. Até então o deslocamento entre as duas cidades só era possível através de diferentes estradas de pequeno porte que faziam as conexóes de forma segmentada entre as cinco cidades localizadas ao longo do percurso - com diversos trechos já incorporados à malha 
urbana das mesmas. A construção da rodovia sP-75 (que recebe diversas nomenclaturas de acordo com diferentes trechos do percurso, embora seja mais conhecida como "rodovia Santos Dumont") potencializou o crescimento econômico e urbano deste eixo inter-regional. Com intersecçóes com diversas outras estradas e vias expressas do estado - sendo as mais importantes com as rodovias Anhanguera (sP-330), Bandeirantes (sP-348), Marechal Rondon (sP-30o) e Castelo Branco (SP-280) - a rodovia Santos Dumont aumentou as possibilidades e a velocidade dos fluxos entre as cidades deste vetor e outras regióes do Estado de São Paulo e outros estados do país. Além da rápida ligação entre as cidades de Campinas, Indaiatuba, Salto, Itu e Sorocaba - e destas com outras regióes -, a rodovia SP-75 também é o principal meio de acesso ao Aeroporto Internacional de Viracopos, na zona sudoeste de Campinas, próximo à divisa com Indaiatuba.

A implantaçáo da rodovia Santos Dumont foi o fator mais determinante no acelerado ritmo de crescimento urbano e demográfico no eixo entre Campinas e Sorocaba a partir da década de 1990, ao induzir à localização de empresas - e seus postos de trabalho - nas cidades acessadas pela rodovia. Como demonstra a tabela 1 , no período de quase três décadas, entre 1991 e 2016, o crescimento demográfico de todos os municípios foi maior do que a média estadual, com exceção de Campinas na década de 1990. O crescimento populacional tem sido especialmente notável na cidade de Indaiatuba, com uma expansão demográfica de duas a três vezes acima da média estadual.

\begin{tabular}{|c|c|c|c|c|}
\hline \multirow[t]{2}{*}{ LOCALIDADES } & \multicolumn{3}{|c|}{$\begin{array}{l}\text { TAXA GEOMÉTRICA DE CRESCIMENTO ANUAL DA } \\
\text { POPULAÇÃO NOS PERÍODOS (EM \% ANUAL) }\end{array}$} & \multirow{2}{*}{$\begin{array}{l}\text { POPULAÇÃ́o } \\
\text { TOTAL (20I6) }\end{array}$} \\
\hline & $2010-2016$ & $2000-2010$ & I99I-2000 & \\
\hline Campinas & 0,96 & 1,09 & 1,54 & 1.142 .620 \\
\hline Indaiatuba & 2,21 & 3,22 & 4,34 & 229.256 \\
\hline Itu & 1,03 & 1,32 & 2,67 & 163.775 \\
\hline Salto & 0,94 & 1,27 & 2,95 & 111.492 \\
\hline Sorocaba & 1,24 & 1,75 & 3,02 & 630.550 \\
\hline Votorantim & 1,02 & 1,27 & 1,99 & 115.495 \\
\hline Total do Estado de SP & 0,85 & 1,09 & 1,82 & 44.749 .699 \\
\hline
\end{tabular}

TABELA I | Crescimento populacional no corredor urbano Campinas-Sorocaba FONTE: FUNDAÇÃo SISTEMA ESTADUAL DE ANÁlise DE DADOS (SEADE) (2OI6)

Como evidencia a figura 3, a dinâmica de expansão urbana recente no corredor urbano também ocorre em ritmo acelerado, em proporção maior do que o crescimento populacional. Entre 2004 e 2016 houve um grande acréscimo de área urbanizada, especialmente nas cidades de Indaiatuba, Salto e Itu, completando um eixo linear de conurbação praticamente ininterrupta entre as cinco cidades, ao longo da rodovia Santos Dumont. A formação deste continuum urbano confirma tendências que já vinham sendo apontadas no início da década passada; "Campinas, aliás, está 
se conurbando com Indaiatuba e esse município com o de Salto. Os bairros de Salto confundem-se com os de Itu e também se encostam aos bairros de Sorocaba” (Lencioni, 2003, p. 36).

A dinâmica recente de expansão urbana está relacionada a mudanças nos padróes de localização de novos loteamentos diferenciando-os do padrão compacto e concêntrico que vigorou no desenvolvimento das metrópoles nacionais até a década de 1980. Predomina atualmente a implantação de empreendimentos urbanísticos de baixa e média densidade construtiva e populacional que passaram a ter na rodovia um dos principais atrativos de localização, com o surgimento e consolidação de condomínios e loteamentos residenciais fechados, dos conjuntos industriais-logísticos e dos shoppings centers como tipologias urbanas predominantes na expansão urbana legal durante o período.

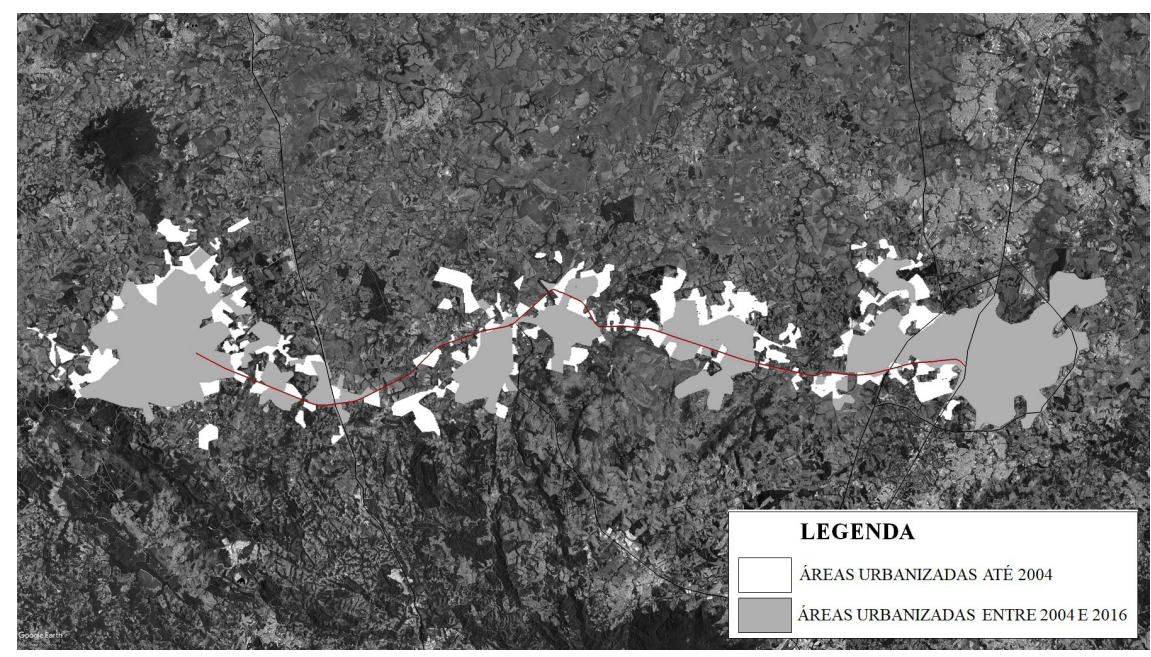

FIGURA 3 | Expansão urbana no corredor Campinas-Sorocaba entre 2004 e 2016 FONTE: ELABORAÇÃo PRÓPRIA COM BASE EM GOOGLE EARTH/LANDSAT (2OI6)

Coexistem assim duas diferentes formas de ocupação do espaço urbano que correspondem, por sua vez, a dois momentos históricos distintos que representam diferentes relaçóes entre os padrôes de crescimento urbano e os elementos técnicos de seus tempos. Por um lado, há áreas com manchas urbanas que apresentam maior contiguidade espacial da malha viária e maior densidade construtiva, organizadas em torno de uma centralidade histórica. Correspondem ao período caracterizado pela "cidade polarizada", tecidos urbanos compactos compostos pelo crescimento centrífugo das áreas periféricas ao redor de uma centralidade urbana histórica (Lacerda, 2012).

Por outro lado, acentua-se a tendência à ocupação dos interstícios entre os núcleos urbanos polarizados através da dispersão de núcleos urbanos ao longo dos principais eixos rodoviários inter-regionais, fragmentados em relação aos tecidos urbanos históricos. Caracteriza-se pela ruptura da continuidade física espacial através da proliferação de núcleos urbanos dispersos e fragmentados, muitas vezes conectados 
ao restante do tecido urbano exclusivamente pelos eixos viários de grande porte que cortam a regiāo, e pela homogeneidade tipológica, predominando os loteamentos e condomínios fechados - tanto de uso residencial como industrial/logístico. Além da descontinuidade espacial, o crescimento urbano contemporâneo nestas áreas se caracteriza também pelo grande porte dos novos loteamentos urbanos, bem maiores em relação às implantaçôes urbanas tradicionais.

Este padrão espacial de crescimento disperso e fragmentado do tecido urbano está bem evidenciado nas duas imagens abaixo, que mostram o crescimento do tecido urbano entre Salto e Itu no período de 2005 a 2016, e entre Indaiatuba e Salto no período de 2008 a 2016 (as diferenças entre os dois recortes temporais selecionados devem-se a qualidade das imagens de satélite disponibilizadas pelo software Google Earth). Apesar do curto recorte temporal, verifica-se que o crescimento do tecido urbano foi bastante significativo. Em ambos os casos, o surgimento de novos loteamentos e núcleos urbanos com localização próxima ou ao longo das margens da rodovia SP-75 foi mais intenso do que o crescimento do tecido urbano de forma contígua aos núcleos urbanos compactos existentes.

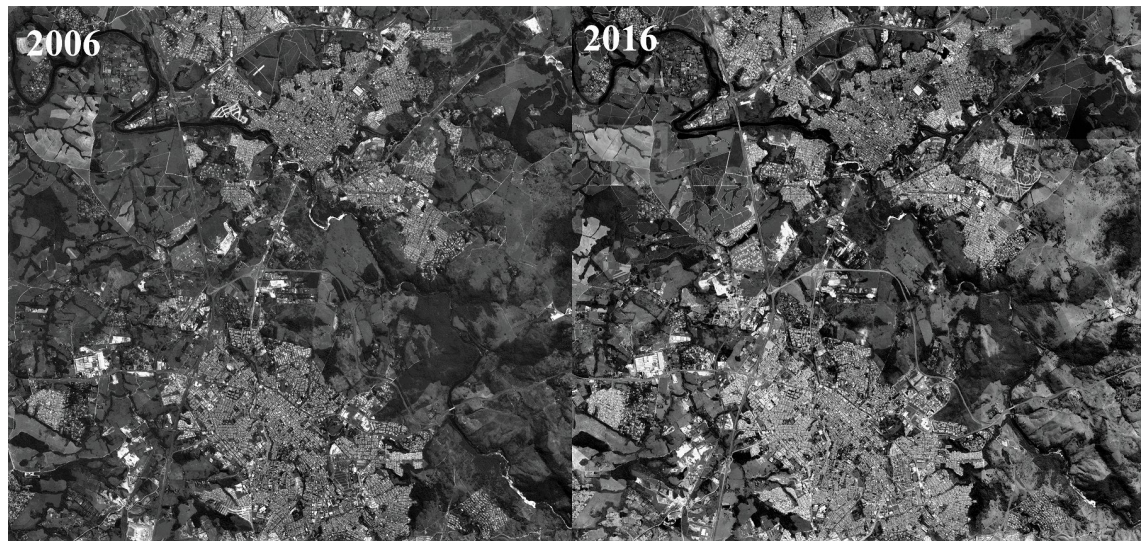

FIgURA 4 | Comparativo sobre a expansão urbana entre as cidades de Itu e Salto, no Estado de São Paulo, entre 2005 e 2016

FONTE: ELABORAÇÃO PRÓPRIA COM BASE EM GOOGLE EARTH/LANDSAT (2OI6)

No caso do mapa da figura 4, fica evidenciado que os loteamentos e condomínios residenciais fechados são a tipologia urbanística mais abundante no crescimento urbano entre os núcleos urbanos centrais de Itu e Salto. Dentre os novos loteamentos destacam-se o Condomínio Terras de São José, Condomínio Xapada de Ytu, Condomínio Palmeiras Imperiais, Jardim Sol d’Icaraí, Condomínio Terras de MontSerrat, Condomínio Terras de Santa Rosa e o Loteamento Ilha de Capri, em sua maioria condomínios fechados que restringem o acesso à população em geral não proprietária de um imóvel condominial. A localização destes novos loteamentos tende a ocupar os vazios urbanos que restavam entre as duas cidades, induzindo um claro processo de conurbação entre elas - conurbação que ocorre através de tipologias urbanas fechadas e, portanto, sem constituir uma malha viária e bairros contínuos entre si. 


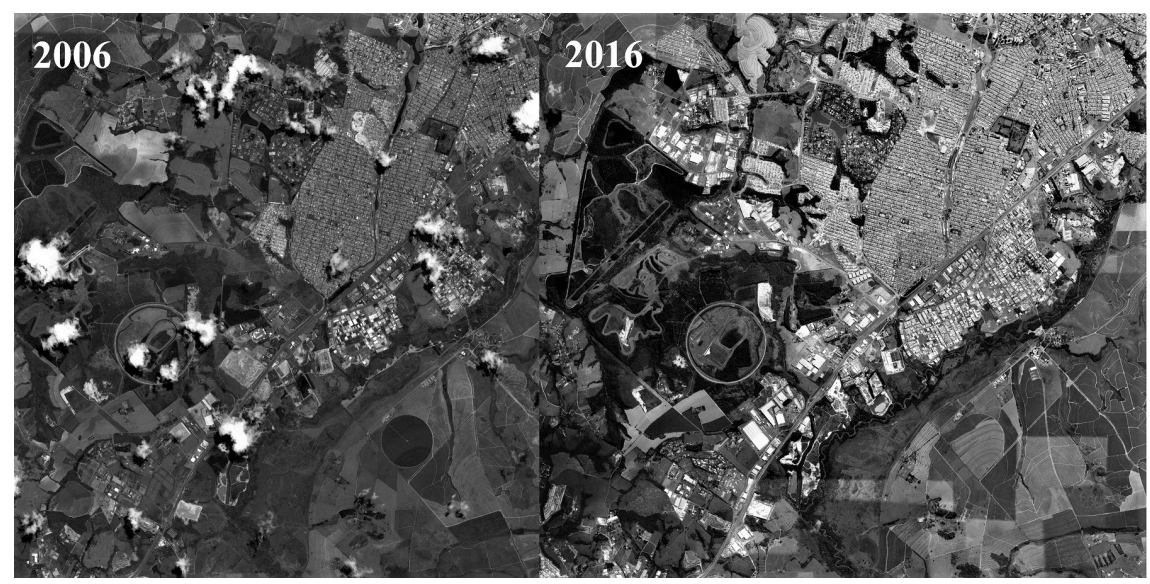

FIGURA 5 | Comparativo sobre a expansão urbana entre as cidades de Salto e Indaiatuba, no Estado de Sáo Paulo, entre 2008 e 2016

FONTE: ELABORAÇÃo PRÓPRIA COM BASE EM GOOGLE EARTH/LANDSAT (20I6)

Já no caso de Indaiatuba, como mostra a segunda figura 5, o predomínio na expansão urbana do período foi de clusters empresariais e logísticos que passaram a ocupar quase toda a margem em ambos os lados da rodovia SP-75, entre os municípios de Indaiatuba e Salto. Caracterizam-se por plantas industriais e logísticas de pequeno e médio porte, e em alguns casos, na constituição de condomínios com pequenos galpóes de usos flexíveis (industrial/logístico/empresarial). Esta tipologia está relacionada à fragmentaçáo da cadeia produtiva e à consequente necessidade de fabricação separada de diversas peças que são transportadas para a montagem em algum determinado ponto do território - e que, com a crescente facilidade de transporte aéreo, pode estar integrada com o mercado produtivo internacional. Nesse sentido o Aeroporto Internacional de Viracopos, localizado a menos de $20 \mathrm{~km}$ destas áreas, configura-se como uma infraestrutura determinante na ocupação do território.

\section{As infraestruturas de transporte e a estruturação do corredor urbano}

O que esta análise aponta é o papel evidente da rodovia SP-75 enquanto principal infraestrutura organizadora do crescimento urbano nestas áreas, não apenas pelas ocupaçóes às suas margens como também nas rodovias transversais que dão acesso a ela. Se as rodovias de grande porte são alvo da localização de empresas industriais e logísticas, as rodovias secundárias são alvo principalmente de loteamentos e condomínios fechados, tipologias que demandam glebas de grandes dimensóes e, nestes locais, encontram um preço da terra mais barato. Esse processo ocorre principalmente no percurso das rodovias Marechal Rondon (SP-300) entre Itu e Porto Feliz, da Estrada Velha (sP-079) entre Itu e Sorocaba e da Estrada Municipal José Boldrini entre Indiaiatuba e Itupeva. Neste último caso, os tecidos urbanos destes municípios estáo praticamente conurbados através de loteamentos residenciais fechados de 
grande porte, demonstrando a alta sinergia do corredor urbano com o Aglomerado Urbano de Jundiaí.

Neste sentido, as distinçóes entre espaço urbano/rural e central/periférico são cada vez mais imprecisas ao analisar a organização espacial deste território. A dispersão de núcleos urbanos desconectados em relação ao tecido urbano compacto cria um mosaico de áreas híbridas entremeando espaços construídos e resquícios rurais, onde estes últimos adquirem cada mais o caráter de reserva de terra para loteamentos futuros do que para atividades agrícolas propriamente ditas. A intensidade da expansão urbana recente indica um elevado potencial de transformação das áreas ainda não urbanizadas localizadas nas proximidades das infraestruturas de transporte de maior porte, especialmente a rodovia SP-75 e o Aeroporto Internacional de Viracopos (que passou por um grande processo de ampliaçáo na última década). Assim, a urbanização toma proporções maiores, abarcando o território regional independentemente do uso urbano ou rural de uma determinada área.

O crescimento urbano ao longo da rodovia SP-75 tende também a alterar dinâmicas históricas de expansão urbana das respectivas cidades ao longo do corredor urbano Campinas-Sorocaba ao direcionar a atuação do mercado imobiliário e fundiário sobre espaços até então periféricos - e onde se localizavam os bairros mais pobres das cidades -, devido à proximidade aos principais eixos viários e à maior disponibilidade de grandes terrenos com o menor preço possível, fatores ideais para a implantação de condomínios e loteamentos fechados. Da mesma maneira, a dispersão de equipamentos terciários de médio e grande porte altera a dinâmica de centralidades na medida em que atrai um grande fluxo diário de pessoas (tanto trabalhadores quanto consumidores), suplantando as centralidades tradicionais em boa parte das atividades urbanas comerciais, de serviços, educacionais, etc.

Os estudos que relacionam o transporte ao processo de organização do território tradicionalmente se enquadram em duas vertentes. A primeira vertente aborda a estruturação do território em escala regional, colocando a capacidade de transporte de mercadorias, informaçóes e capital como um dos principais elementos que definem as diferenciaçóes entre as regióes. A segunda relaciona o transporte às dinâmicas de valorização do espaço urbano - em si, como mercadoria, neste caso gerada pela maior capacidade de acessibilidade de um determinado ponto do espaço intra-urbano, atuando "na luta de classes pela apropriação diferenciada das vantagens e desvantagens do espaço construído e na segregação espacial dela resultante" (Villaça, 2001, p. 45). Neste sentido se poderia afirmar que:

A estruturação do espaço regional é dominada pelo deslocamento das informações, da energia, do capital constante e das mercadorias em geral [...]. O espaço intra-urbano, ao contrário, é estruturado fundamentalmente pelas condições de deslocamento do ser humano, seja enquanto portador da mercadoria força de trabalho como no deslocamento casa/trabalho -, seja enquanto consumidor - reprodução da força de trabalho, deslocamento casa-compra, casa-lazer, etc. (Villaça, 2001, p. 20)

Contudo, essa sentença corresponde ao caso da urbanização concentrada onde o "ponto intra-urbano" é o fator mais preponderante nas dinâmicas de valorização do espaço. Já nas regióes onde contemporaneamente predominam as tendências de 
dispersão pelo território regional de núcleos urbanos espacialmente fragmentados, a relação entre o transporte e as escalas intra-urbana e regional se misturam. As condiçôes socioculturais da vida urbana contemporânea - desde a acessibilidade da maior parcela da populaçáo ao transporte individual e à indústria cultural promotora da "vida suburbana" - potencializa o papel da rodovia regional na mobilidade urbana. Neste sentido, a proximidade às rodovias é um dos fatores mais preponderantes na atração de novos núcleos urbanos, especialmente das tipologias e equipamentos urbanos de grande porte, como os condomínios residenciais, os "shopping centers" e os conjuntos logístico-industriais, que acabam por conformar vetores de maior intensidade de expansão urbana, como o corredor urbano Campinas-Sorocaba. Podemos afirmar então que, mais do que os "pontos", os "eixos" passam a se constituir como os componentes de maior impacto na estruturação da urbanização em escala regional.

Sendo assim, a distribuição dos investimentos em áreas próximas às infraestruturas inter-regionais de transporte tem um papel particularmente importante na urbanização contemporânea e não apenas nas dinâmicas de diferenciação regional. Essa não é propriamente uma novidade; desde a consolidação da rede ferroviária paulista no século XIX, os investimentos na rede estadual de transporte provocaram transformaçôes importantes na organização territorial, derivando na maior intensidade de urbanização de alguns centros urbanos em detrimento da "desurbanização" de outras cidades e regióes. A novidade no atual período é a escala e a intensidade deste processo; náo é o crescimento de cidades e metrópoles o principal fenômeno, mas sim a formação de continuum urbano-regionais compostos pela disseminação de núcleos urbanos dispersos em escala regional.

De acordo com o planejamento estadual para a Macrometrópole Paulista, há uma clara intenção de consolidação de um vetor de elevada atração de investimentos econômicos de capital privado entre as regióes de Campinas e Sorocaba, ao longo da rodovia sP-75, como aponta a figura 6. Denominado como "Vetor de Desenvolvimento Perimetral”, inclui, além do vetor entre Sorocaba e Campinas, a ligação até São José dos Campos e São Sebastião (sede portuária), e terá como foco a atração das atividades econômicas mais modernas, visando "contribuir para apoiar os processos de difusão de inovação tecnológica e geração de conhecimento, ampliando a competitividade sistêmica da economia regional e o poder de atraçáo de investimentos" (Empresa Paulista de Planejamento Metropolitano s.A. [Emplasa]), 2015b, p. 23).

As infraestruturas de transporte são os elementos que fundamentam a intenção de estruturar um sistema multimodal de escoamento da produção de mercadorias neste vetor, articulando as plataformas logísticas de Sorocaba, Campinas e São José dos Campos, o Aeroporto Internacional de Viracopos e o Porto de São Sebastião. Os investimentos no vetor perimetral são maciços, principalmente na duplicação da rodovia SP-99 Tamoios (que interliga a região metropolitana do Vale do Paraíba ao litoral), cuja duplicação do trecho de planalto foi entregue em 2014, e o trecho de serra encontra-se em obras com um custo de aproximadamente R \$ 3 bilhôes, e o constante investimento na expansão do porto de São Sebastiáo. Outros investimentos de grande porte também estão nos planos por parte do Estado, como 
a construção de ligaçóes ferroviárias de passageiros entre Sorocaba, Campinas e a capital, e uma conexão de cargas para o porto de São Sebastião.

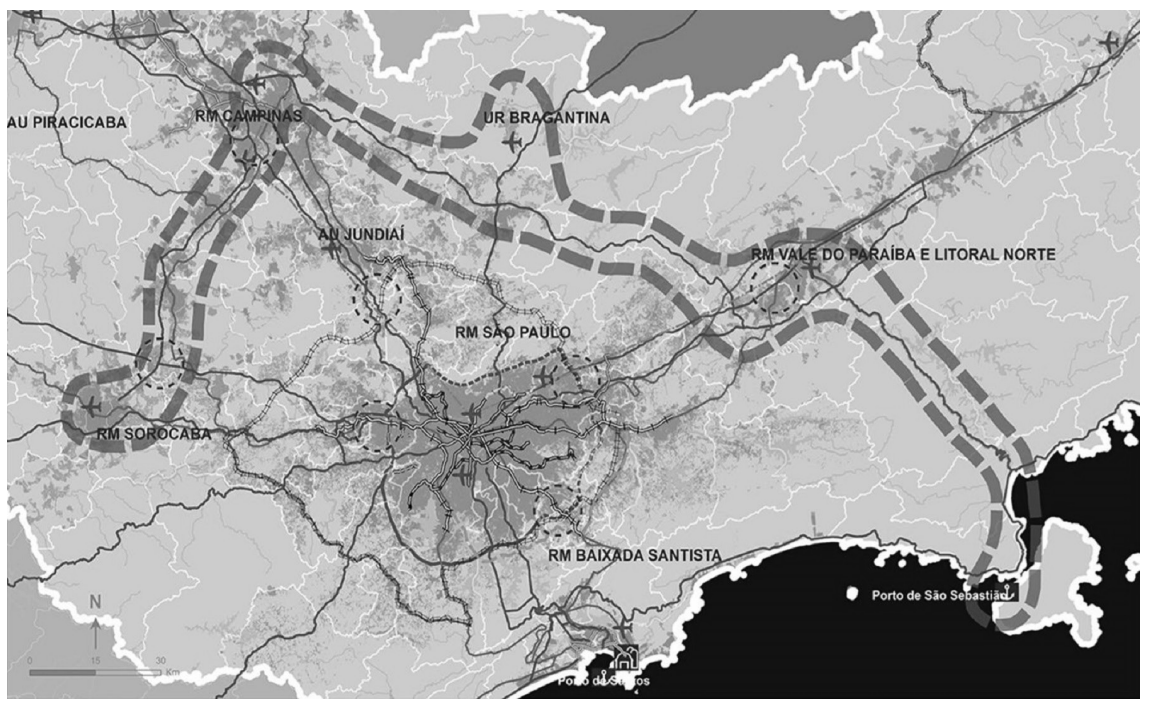

FIGURA 6 | Vetor de desenvolvimento perimetral

FONTE: EMPRESA PAULISTA DE PLANEJAMENTO METROPOLITANO S.A. (EMPlasa) (2O I 5A)

A regiáo de Campinas é, dentre as regióes do Vetor de Desenvolvimento Perimetral, a de maior expressão produtiva, sendo o principal polo logístico do estado - confirmado ainda mais pela expansão do Aeroporto de Viracopos - devido à confluência de diversas rodovias, ramais ferroviários que atrai a localização de diversas montadoras de veículos e empresas logísticas na regiáo. A ligação com Sorocaba tende a intensificar a produção industrial neste eixo, cabendo "ressaltar que o eixo CampinasSorocaba já foi "descoberto" pelo setor industrial, sendo importante a concentração de empresas ali instaladas e em vias de instalação” (Emplasa, 2015a, p. 25).

$\mathrm{O}$ constante investimento em infraestrutura vem derivando em um constante crescimento da produção industrial no corredor urbano nas últimas décadas. Ambas as regióes apresentaram um crescimento muito maior que a média estadual no número de empregos formais na indústria, 49,4\% na Região de Governo de Campinas e $51 \%$ na de Sorocaba ${ }^{1}$, frente aos $12 \%$ no Estado de São Paulo entre 1991 e 2014. A RG de Campinas passou a representar de 8 para 10,68\% e a RG de Sorocaba de 3,79\% para 5\% no total de empregos industriais no estado neste período. Estes números demonstram que, apesar do processo geral de diminuição da proporção de empregos industriais face a "terceirização" da produção industrial e ao crescimento do setor de serviços - especialmente na Região Metropolitana de São Paulo -, as regióes de Campinas e Sorocaba continuam recebendo novas indústrias e

$1 \longdiv { \text { Como ambas as Regiōes Metropolitanas ainda não existiam em 1991, os dados são disponibilizados } }$ de acordo com as Regióes de Governo, que são semelhantes à composição atual das regióes metropolitanas do Estado. 
consolidando-se como os principais centros produtivos do estado depois da Grande São Paulo (Seade, 2016).

Os setores de alta tecnologia são destaque em ambas as regiōes. A Região de Governo de Campinas era responsável por mais da metade (51,3\%) do Valor Adicionado Total da Indústria (vat) de Material Eletrônico e Equipamentos de Comunicaçóes do Estado, e 15,9\% do vat de Máquinas para Escritório e Equipamentos de Informática, enquanto a RG respondia por 13,9\% neste setor em 2015. No total, as regiôes de Campinas e Sorocaba juntas já respondiam, em 2015, por um terço $11,2 \%$ do total do produto industrial nacional, mais do que o Estado de Minas Gerais, o segundo estado brasileiro mais industrializado (Seade, 2016).

A concentração econômica nestas regiōes - bem como em toda a extensão da Macrometrópole Paulista - ocorreu mediante o contínuo investimento estatal em infraestrutura desde a segunda metade do século xx. A alta densidade de rodovias entre Campinas e Sorocaba - com destaque para os sistemas Anhanguera/Bandeirantes, Raposo Tavares/Castelo Branco e Rodovia Santos Dumont -, e a expansão do Aeroporto Internacional de Viracopos em Campinas são fatores centrais na formação contemporânea de um corredor industrial de alta tecnologia entre as duas regiôes. A concentração de multinacionais asiáticas já rendeu a alcunha de "corredor asiático" devido a concentração de multinacionais japonesas, sul-coreanas e chinesas neste vetor territorial, como a Toyota, Hyundai, Honda, Stanley, Sumitomo, LG, Samsung, Huawei, Lenovo, zTE, CJ e Ajinomoto (Leite, 2013).

\section{Consideraçóes finais}

A formação de um corredor urbano entre Campinas e Sorocaba evidencia a maior complexidade territorial do atual estágio do processo de metropolização no Estado de São Paulo. O fenômeno de urbanização linear entre dois polos regionais em um eixo que não faz a ligação direta com a capital do estado indica a maior autonomia das dinâmicas de expansão urbana em escala territorial, bem como a constituição de novas articulaçôes metropolitanas que se sobrepóem às tradicionais hierarquias regionais históricas. Revela também condiçóes de fluxos de mercadorias na rede de transportes do Estado de Sáo Paulo que destaca equipamentos de escoamento da produção, como o Aeroporto Internacional de Viracopos e o Porto de São Sebastião, não demandando mais a passagem pela Grande Sáo Paulo.

A ideia de "corredor" expressa a compreensão da urbanização estruturada ao longo de eixos e vetores em escala regional ao invés de cidades-polo e centralidades pontuais. O fenômeno empírico é um indicativo de transformaçóes na estrutura de produção e nas relações sociais contemporâneas; as diferenças não são apenas na forma espacial, mas na dimensão e escala da organização espacial. Por "corredor urbano" denota-se a continuidade inter-regional do processo de urbanizaçáo, e o entendimento da estruturação urbana cada vez mais organizada pela presença das infraestruturas de transporte e circulação de diversas naturezas (linhas), e menos pelas centralidades urbanas históricas (pontos). Constitui-se em uma complexa articulação urbano-regional que simultaneamente promove a integração em escala regional, a partir da fragmentação do espaço intra-urbano, abrangendo tanto 
os novos tecidos urbanos dispersos e fragmentados relacionados diretamente à expansão rodoviária, quanto as localidades históricas locais surgidas em um outro padrão de circulação e mobilidade.

Endossam-se entáo os estudos e vertentes urbanísticas que enxergam a crescente combinação entre cidade e região no atual período de urbanização, acreditando-se não ser mais possível entender os fenômenos mais recentes de articulaçóes urbano-regionais relacionando urbano e regional como duas categorias de análise distintas. Questionam-se assim as habituais distinçôes conceituais entre urbano/rural, cidade /região, centro/periferia, na medida em que se o espaço urbano deixa de estar circunscrito nos claros limites da cidade ou da metrópole e se dissemina de forma dispersa e fragmentada em escala regional, alterando as tradicionais hierarquias de centralidades e as dialéticas espaciais entre os lugares de ricos e pobres no contexto da cidade-região.

As novas dinâmicas do mercado imobiliário passam a disputar áreas que até então concentrava a população mais pobre da cidade e que, nas tipologias predominantes de loteamentos residenciais fechados, induzindo à ampliação da segregação social da população de menor renda a partir da autosegregação das classes sociais de maior renda. A proximidade espacial entre a parcela mais rica e mais pobre da populaçáo tem nos altos muros dos condomínios fechados uma barreira física e simbólica que dificultam ainda mais a mobilidade e acessibilidade urbana da parcela mais pobre de população, com menor poder aquisitivo para usufruir dos rápidos fluxos promovidos pelos automóveis individuais e pelas rodovias.

O corredor urbano Campinas- configura, portanto, uma nova organização regional própria do atual período de globalizaçáo, estruturada segundo as açôes dos agentes econômicos multinacionais. A formação deste eixo urbano corresponde ao processo de "fragmentação das unidades regionais historicamente construídas", de acordo com a "lógica da constituição do meio técnico-científico-informacional", configurando "territorialidades contínuas, horizontalidades para a interação técnico-econômica do novo mercado" (Silva Neto, 2003, p. 14). É evidente que a atual dinâmica socioespacial urbana transcende os limites da regionalização existente, sejam as das regióes administrativas e de governo, ou as metropolitanas.

O Estado resigna-se cada vez mais a ser o fornecedor de infraestrutura territorial para dar suporte à instalação das grandes empresas (geralmente multinacionais) que, estas sim, acabam por desenhar as novas relaçóes regionais de acordo com as estratégias de localização geográfica. Neste sentido as tradicionais regionalizaçôes enfraquecem-se à medida que tais empresas passam a tecer relaçóes diretas com a rede globalizada de produção e distribuição graças, claro, à difusão das tecnologias de informação (Benko, 1999). Enfraquece-se o papel das centralidades urbanas tradicionais na proporçáo em que se fortalece a atribuiçáo dos grandes suportes de logística e circulação. Entende-se assim a formação de um corredor urbano entre Campinas e Sorocaba, como a manifestação da regionalização em funçáo dos sistemas de engenharia, redefinindo as tradicionais relaçôes regionais baseadas numa hierarquia rígida entre as cidades-polo e as respectivas áreas de alcance regional. 


\section{Referências bibliográficas}

Benko, G. (1999). Economia, espaço e globalização na aurora do século XXI. Sáo Paulo: Hucitec.

Boddy, M. (1990). Reestruturaçáo industrial e novos espaços industriais: uma crítica. Em E. Preteceille \& L. Valadares, Reestruturação Urbana: tendências e desafios (pp. 8-30). São Paulo: Nobel/Instituto Universitário de Pesqisas do Rio de Janeiro (Iuperj).

Cano, W. (2007). Raizes da concentração industrial em São Paulo. Campinas: Instituto de Economia/Editora da Universidade Estadual de Campina (Unicamp).

Castells, M. (1999). A sociedade em rede. São Paulo: Paz e Terra.

Correia, T. D. (2009). Philip Gunn: debates e proposiçöes em arquitetura, urbanismo e território na era industrial. São Paulo: Annablume/Fapesp.

Empresa Paulista de Planejamento Metropolitano s.A. (emplasa) (2015a). Plano de Ação da Macrometrópole Paulista 2013-2040 - O futuro das metrópoles paulistas. São Paulo: Emplasa/Secretaria Estadual da Casa Civil/Governo do Estado de São Paulo [estado]. https://bibliotecavirtual.emplasa.sp.gov.br/AbrirArquivo.aspx?ID=20360.

Empresa Paulista de Planejamento Metropolitano S.A. (emplasa) (2015b). Plano de Ação da Macrometrópole Paulista 2013-2040 - Uma visão da Macrometrópole. São Paulo: Emplasa/Secretaria da Casa Civil/ Governo do Estado de São Paulo, sp. https:// bibliotecavirtual.emplasa.sp.gov.br/AbrirArquivo.aspx?ID=20359.

Fundaçáo Sistema Estadual de Análise de Dados (Seade) (2016). Informação dos Municípios Paulistas. São Paulo. www.imp.seade.gov.br/frontend/\#/

Harvey, D. (2005). A produção capitalista do espaço. São Paulo: Annablume.

Lacerda, N. (2012). Fragmentaçấo e integração: A metrópole hoje. Em A. C. Ribeiro, E. Limonad, \& P. P. Gusmão, Desafios ao Planejamento (pp. 21-42.) Rio de Janeiro: Letra Capital. http://www.anpur.org.br/publicacao/arquivos/desafios-ao-planejamento.pdf

Leite, A. (2013 abril 20). Polo Campinas-Sorocaba já é 20 maior PIB: Eixo conhecido por “corredor asiático" supera estados como Minas e Rio. Correio Popular. http://correio. rac.com.br/_conteudo/2013/04/capa/campinas_e_rmc/50995-polo-campinassorocaba-ja-e-2-maior-pib.html

Lencioni, S. (2003). Uma nova determinação do urbano: o desenvolvimento do processo de metropolizaçáo do espaço. Em A. F. Carlos \& A. I. Lemos, Dilemas Urbanos: Novas abordagens sobre a cidade (pp. 35-44). São Paulo: Contexto.

Queiroga, E. (2001). A megalópole e a praça: o espaço entre a razão de dominação e a ação comunicativa. São Paulo: Tese de doutorado em Arquitetura e Urbanismo, Universidade de São Paulo, São Paulo, sp, Brasil. https://bit.ly/2rg6I92

Raposo, M. R. (2012). Condomínios fechados, tempo, espaço e sociedade: uma perspectiva histórica. Cadernos Metrópole, 14(27), 171-196. https://doi.org/10.1590/14786

Santos, M. (1994). A urbanização brasileira. São Paulo: Hucitec.

Secchi, B. (2015). Primeira lição de urbanismo. Sáo Paulo: Perspectiva.

Silva Neto, M. L. (2003). Regionalização histórico-administrativa versus regionalização unificadora-complexa: reflexóes sobre as tendências da organização regional paulista. $x$ Encontro Nacional da Anpur, pp. 1-17.

Singer, P. (1973). Economia Política da Urbanização. São Paulo: Brasiliense/ Centro Brasileiro de Análise e Planejamento (CEBraP). 
Villaça, F. (2001). O espaço intra-urbano no Brasil. São Paulo: Studio Nobel; Fundação de Amparo à Pesquisa do Estado de São Paulo (FAPESP); Lincoln Institute. https://bit. ly/2LLUoda 